\title{
Is Deficiency of 25-Hydroxy Vitamin D A Risk Factor for Autism? A Preliminary Study
}

\author{
Megahed M. Hassan', Ahmed Mamdouh Emam ${ }^{1}$, Ashraf Abou-Taleb ${ }^{2}$, \\ Amany Abdelrahman ${ }^{3}$, Sameh Salahelden ${ }^{4}$ and Montasser M. Mohamed ${ }^{2}$ \\ Original \\ Amany Abdelrahman', Sameh Salahelden' and Montasser M. Mohamed \\ ${ }^{1}$ Department of Phoniatrics Unit Otolaryngology, ${ }^{2}$ Department of Pediatrics, ${ }^{3}$ Department of \\ Physiology, Faculty of Medicine, Sohag University \\ ${ }^{4}$ Department of Medical Biochemistry, Faculty of Medicine, Assuit Alazhar University
}

\begin{abstract}
Objective: To investigate the status of 25-hydroxy-vitamin-D [25-(OH)-D] in autistic children and to correlate with their mothers vitamin statuses and autism severity.

Methods: In this case-control study, serum 25(OH)-D was measured in autistic children and controls $(\mathrm{n}=36 \mathrm{each})$ and in mothers of autistics and control mothers $(\mathrm{n}=24$ each). Comparison and correlation studies were performed.

Results: Both autistic children and their mothers have lower 25-(OH)-D compared to their controls with significant differences ( $P<0.001$ for children and $P=0.025$ for mothers). Vitamin statuses in both autistic children and their mothers showed moderate to strong positive correlation $(P<0.001)$. Moreover, the $25-\mathrm{OH}-\mathrm{D}$ showed inverse correlation with the autism severity $(P=0.0026)$.

Conclusion: Deficiency of 25(OH)-D is common in autistic children and related to the severity of symptoms. Vitamin $\mathrm{D}$ deficiency in children might be maternal-dependent. Deficiency of 25(OH)-D in autistic children and their mothers could be the primary predisposing factor for autism. This may find a common link among the genetic, immunological, anatomical, biochemical and physiological factors putting the puzzles together. Early supplementation of vitamin D could improve autistic manifestations.
\end{abstract}

Key Words: 25(OH)-D; ASD' mothers; autism; common factor; predisposing factor.

Received: 28 September 2020, Accepted: 03 February 2021

Corresponding Author: Megahed Mohamed Hassan, Department of Phoniatrics Unit, Otolaryngology, Faculty of Medicine, Sohag University, Sohag, Egypt, Tel.: +966 500418363, E-mail: megahed_hassan@med.sohag.edu.eg

ISSN: 2090-0740, 2021

\section{INTRODUCTION}

Autism Spectrum Disorders (ASD) are complex neurodevelopmental disorders characterized by repetitive behavior and impaired communication and social interactions with variable degrees across autistics ${ }^{[1,2]}$. The exact etiology of the ASD is still unknown. Many different factors were accused. Genetic factors were addressed and confirmed by family and twins studies ${ }^{[3,4,5]}$. Also, environmental factors were reported extensively. These factors included low birth weight ${ }^{[6]}$, intra-partum hypoxia ${ }^{[7]}$, in-utero exposure to certain drug especially anticonvulsants $^{[8]}$, intrauterine infection ${ }^{[9]}$ and maternal vitamin D deficiency ${ }^{[10]}$. Also, immunological factors were reported and explained by the immune dysregulation and autoimmune reactivity which may cause ASD. Some genetic studies have indicated a link between ASD and genes that are relevant to both nervous and immune systems. Alterations in these 2 pathways (nervous and immune) can affect function in both systems ${ }^{[10]}$.

Low level of 25(OH)-D can be caused by a number of factors; lack of exposure to sunlight, intake of food poor in vitamin $\mathrm{D}$ or poor absorption as in inflammatory bowel disease, liver and kidney diseases and genetic factors ${ }^{[11]}$.

Deficiency of Vitamin-D in the early life affects neuronal differentiation, axonal connectivity, dopamine ontogeny, and brain structure and function. This early deficiency was associated with psychiatric conditions with a developmental basis such as $\mathrm{ASD}^{[12,13]}$. Also, maternal vitamin-D status was implicated in the etiology of ASD with comorbid intellectual disability ${ }^{[14]}$. However, causality was not confirmed. Also, correlation between vitamin D statuses in autistic children and their mother is lacking. Such correlation is important to investigate for any developmental deficiency of vitamin D particularly in absence of other causes of vitamin deficiency.

In the current study, the status of $25(\mathrm{OH})-\mathrm{D}$ in autistic children was compared to a matched control group of typically developed children. Also, 25(OH)-D in mothers of autistic children was compared to that of mothers of control children. In addition, a correlation between 25(OH)-D statuses in autistic children and their mothers was carried out. Moreover, a correlation between severity 
of ASD and serum 25(OH)-D status in autistic children was conducted. The aim of this research is to find out whether the 25(OH)-D statuses in children and their mothers are related to each other and whether these statuses have impacts on the occurrence and severity of ASD.

\section{MATERIAL AND METHODS}

In this case-control study, all patients were recruited form Phoniatrics and Pediatrics clinics at Sohag University Hospital, Egypt. Thirty six children were diagnosed ASD in the period from November 2017 to February 2019. This study included 36 ASD children (age range 2-8 years, mean 4, SD 1.5) and 36 control children (age range 2.5-8 years, mean 4.67, SD 1.52). Age and sex distribution of all participants were shown in (Table 1). The inclusion criterion of our subjects is delayed language development with clinical diagnosis of ASD. Both subjects and control children were normally but not exclusively breast-fed with good exposure to sunlight. Any subject or control children with history of low birth weight and malnutrition were excluded. Mothers used antiepileptic medications during pregnancy were excluded from the start. The evaluation was done by 4 experienced Physicians in (Pediatrics and Phoniatrics specialties) through proper history taking and direct observation of every child in an interdisciplinary setting. Diagnosis of ASD and severity rating were made by clinical observation and the Diagnostic Statistical Manual 5 (DSM-V) $)^{[15]}$. In addition to the diagnosis, ASD children were rated into levels 1, 2 and 3 according to DSM-V. Further evaluation was carried out by Gilliam ASD Rating Scale (GARS) ${ }^{[16]}$. These children were rated into 6 categories according to both GARS score and clinical evaluation based on the degree of communicative impairment and stereotyped behavior as mentioned in DSM-5 rating (Table 2). So, the severity rating based on GARS, DSM-5 and clinical evaluation. The clinical evaluation was considered in few cases (6) where overlapping happen or when scoring by GARS and DSM-5 did not goes together as illustrated in the (Table 2). Only 5 children did not undergo GARS assessment because their ages lie between $2-3$ years; so, only their clinical evaluations were considered. The ASD' mothers and control mothers with matched age and socioeconomic status underwent laboratory $25(\mathrm{OH})$ vitamin D measurements. Because there are only 24 ASD' mothers completed their laboratory measurements; so, matched number from the control mothers was considered for the comparison. A control group of 36 typically developed children with matched age, sex and socioeconomic status were investigated for serum $25(\mathrm{OH})-\mathrm{D}$ and calcium as well.

Table 1: Descriptive statistics of the personal data

\begin{tabular}{|c|c|c|c|c|c|}
\hline & & Total ASD children & Control children & ASD' mothers & Control mothers \\
\hline \multicolumn{2}{|r|}{ Total No } & 36 & 36 & 24 & 24 \\
\hline \multicolumn{2}{|r|}{ Females } & 7 & 6 & - & - \\
\hline \multicolumn{2}{|r|}{ Males } & 29 & 30 & - & - \\
\hline \multirow{4}{*}{$\stackrel{80}{\gtrless}$} & Max & 8 & 8 & 42 & 47 \\
\hline & Min & 2 & 2.5 & 20 & 23 \\
\hline & Mean & 4 & 4.67 & 27.75 & 31.5 \\
\hline & $\mathrm{SD}$ & 1.5 & 1.52 & 7.39 & 8.9 \\
\hline \multicolumn{2}{|c|}{ Unpaired t-test for ages } & \multicolumn{2}{|c|}{$\mathrm{P}=0.102, \mathrm{t}=1.66, \mathrm{df}=70$} & \multicolumn{2}{|c|}{$\mathrm{P}=0.116, \mathrm{t}=1.6, \mathrm{df}=46$} \\
\hline
\end{tabular}

Table 2: The rating scale of ASD in relation to GARS and DSM-5 scores

\begin{tabular}{cccc}
\hline GARS score & DSM-5 score & Rating scale & No. of subjects (\%) \\
\hline Less than 70 & & 1 & $2(5.6 \%)$ \\
$70-79$ & Level 1 & 2 & $4(11.1 \%)$ \\
$80-89$ & & 3 & $3(8.3 \%)$ \\
$90-110$ & Level 2 & 4 & $6(16.6 \%)$ \\
$111-120$ & Level 3 & 5 & $4(11.1 \%)$ \\
More than 120 & & 6 & $17(47.2 \%)$ \\
\hline
\end{tabular}

\section{Estimation of $25 \mathrm{OH}-\mathrm{D}$}

About $5 \mathrm{ml}$ venous blood samples were withdrawn from all children and 24 mothers of the study under aseptic condition. These samples were put in a sterile plain vacationer for vitamin-D investigation. Estimation of serum 25(OH)-D was performed on ARCHITECT i2000SR System using ARCHITECT 25(OH)-vitamin-D kits supplied by Abbott. The 25(OH)-D was estimated by a chemiluminescent microparticle immunoassay (CMIA) technology. The overall distribution of $25(\mathrm{OH})-\mathrm{D}$ levels was stratified by 3 breakpoints: $<30 \mathrm{ng} / \mathrm{ml},<20 \mathrm{ng} / \mathrm{ml}$, and $<10 \mathrm{ng} / \mathrm{ml}$ creating 4 levels or statuses. Vitamin-D status was defined as average ( $\geq 30 \mathrm{ng} / \mathrm{ml})$, insufficiency $(20-29 \mathrm{ng} / \mathrm{ml})$, deficiency $(10-19 \mathrm{ng} / \mathrm{ml})$ and severe deficiency $(<10 \mathrm{ng} / \mathrm{ml})^{[17]}$. 


\section{Statistics}

The unpaired t-test (two-tailed) was used in comparison of the measurements between autistic and the control children as well as between ASD's mothers and control mothers. The parametric Pearson test was used to correlate between $25(\mathrm{OH})$-D statuses in autistic children and their mothers. Lastly, the non-parametric Spearman test was applied for correlation between the status of the 25(OH)-D in autistic children and the severity of ASD because the severity is non-continuous (discrete data). The statistical software program (GraphPad Prism 7) was used for data analysis and graph making.

\section{Ethical considerations}

All methods and procedures were conducted according to the Institutional Review Board of the Faculty of Medicine, Sohag University. Also, the study was approved by the Ethical Committee of the Faculty. Written informed consents were obtained from all parents.

\section{RESULTS}

The descriptive statistics including age and sex distributions of children and mothers groups were shown in Table (1). Both ASD and control children groups were matched in sex and ages. Similarly, both ASD' and control mothers groups were matched in age as shown in Table (1) by the insignificant differences. The 25(OH)-D statuses revealed significant differences between the 2 children groups as well as between the 2 mother groups as shown in the corresponding figures.
Table (1) shows descriptive statistics of the personal data (age, number and sex distributions). Abbreviations; ASD: Autism Spectrum Disorder, ASD's mothers: mothers of Autism Spectrum Disorder children, No: number of subjects, Max: Maximum, Min: Minimum, SD: Standard Deviation.

Table (2) shows the rating scale of ASD severity in relation to GRBAS and DSM-5 scores, where scale (1) represents weak possibility and (6) represents strong possibility to have ASD. This 6 points scale was used for statistical analysis related to ASD severity where 5 and 6 represent severe ASD (level 3); while, the scores (4) represent moderate ASD (level 2) and (1-3) represent mild ASD (level 1). Each DSM-5 level was further rated into 2 scales clinically.

Table (3) shows the descriptive statistics of both ASD and control children groups for age and $25(\mathrm{OH})$-vitamin-D statuses (Severe deficiency, deficiency, insufficiency and average). Abbreviations: No; number, Min; minimum, Max; maximum, SD; standard deviation, ASD; Autism Spectrum Disorder.

Table (4) shows the descriptive statistics of both ASD' and control mother groups for age and $25(\mathrm{OH})$-vitamin-D statuses (Severe deficiency, deficiency, insufficiency and average). Abbreviations: No; number, Min; minimum, Max; maximum, SD; standard deviation, ASD; Autism Spectrum Disorder.

Table 3: Descriptive statistics of number, age and vitamin $\mathrm{D}$ level in children

\begin{tabular}{|c|c|c|c|c|c|c|c|}
\hline \multirow{2}{*}{$25(\mathrm{OH})$ Vitamin D level distribution } & \multirow{2}{*}{ Statistics } & \multicolumn{3}{|c|}{ ASD children } & \multicolumn{3}{|c|}{ Control children } \\
\hline & & $25(\mathrm{OH})$ vit $\mathrm{D}$ & Age in year & No. & $25(\mathrm{OH})$ vit $\mathrm{D}$ & Age in year & No. \\
\hline \multirow{4}{*}{$\begin{array}{l}\text { Severe deficiency } \\
25(\mathrm{OH}) \text {-vitamin-D }<10 \mathrm{ng} / \mathrm{ml}\end{array}$} & Min & 4.7 & 2 & \multirow{4}{*}{10} & & & \multirow{4}{*}{0} \\
\hline & Max & 9.8 & 7.5 & & & & \\
\hline & Mean & 6.6 & 3.8 & & & & \\
\hline & $\mathrm{SD}$ & 1.4 & 1.7 & & & & \\
\hline \multirow{4}{*}{$\begin{array}{l}\text { Deficiency } \\
\text { 25(OH)-vitamin-D: } 10-19 \mathrm{ng} / \mathrm{ml}\end{array}$} & Min & 10.1 & 2 & \multirow{4}{*}{17} & 14 & 2.5 & \multirow{4}{*}{4} \\
\hline & Max & 19.7 & 8 & & 18 & 5.5 & \\
\hline & Mean & 13.4 & 4.2 & & 15.6 & 4.4 & \\
\hline & $\mathrm{SD}$ & 2.8 & 1.5 & & 1.9 & 1.4 & \\
\hline \multirow{4}{*}{$\begin{array}{l}\text { Insufficiency } \\
25(\mathrm{OH}) \text {-vitamin-D: } 20-29 \mathrm{ng} / \mathrm{ml}\end{array}$} & Min & 20.6 & 3 & \multirow{4}{*}{6} & 22 & 3 & \multirow{4}{*}{6} \\
\hline & Max & 28 & 7 & & 28 & 4.75 & \\
\hline & Mean & 24.4 & 4.2 & & 25.2 & 4.2 & \\
\hline & $\mathrm{SD}$ & 2.5 & 1.7 & & 2.4 & 0.8 & \\
\hline \multirow{4}{*}{$\begin{array}{l}\text { Average } \\
25(\mathrm{OH}) \text {-vitamin-D } \geq 30 \mathrm{ng} / \mathrm{ml}\end{array}$} & Min & 30.5 & 2.5 & \multirow{4}{*}{3} & 31 & 2.5 & \multirow{4}{*}{26} \\
\hline & Max & 63.5 & 6 & & 70 & 8 & \\
\hline & Mean & 48.7 & 3.8 & & 47.3 & 4.8 & \\
\hline & SD & 16.8 & 1.8 & & 9.3 & 1.5 & \\
\hline
\end{tabular}


Table 4: Descriptive statistics of number, age and vitamin D level in mothers

\begin{tabular}{|c|c|c|c|c|c|c|c|}
\hline \multirow{2}{*}{$25(\mathrm{OH})$ Vitamin D level distribution } & \multirow{2}{*}{ Statistics } & \multicolumn{3}{|c|}{ ASD mothers } & \multicolumn{3}{|c|}{ Control mothers } \\
\hline & & $25(\mathrm{OH})$ vit $\mathrm{D}$ & Age in year & No. & $25(\mathrm{OH})$ vit $\mathrm{D}$ & Age in year & No. \\
\hline \multirow{4}{*}{$\begin{array}{l}\text { Severe deficiency } \\
25(\mathrm{OH}) \text {-vitamin-D }<10 \mathrm{ng} / \mathrm{ml}\end{array}$} & Min & 3.6 & 20 & \multirow{4}{*}{14} & 4.2 & 23 & \multirow{4}{*}{14} \\
\hline & Max & 8.7 & 42 & & 8.9 & 47 & \\
\hline & Mean & 6.12 & 29.7 & & 6.24 & 33.26 & \\
\hline & $\mathrm{SD}$ & 1.6 & 9 & & 1.56 & 9.32 & \\
\hline \multirow{4}{*}{$\begin{array}{l}\text { Deficiency } \\
\text { 25(OH)-vitamin-D: } 10-19 \mathrm{ng} / \mathrm{ml}\end{array}$} & Min & 10.1 & 22 & \multirow{4}{*}{10} & 10 & 27 & \multirow{4}{*}{5} \\
\hline & Max & 15 & 28 & & 16.5 & 40 & \\
\hline & Mean & 12.1 & 25 & & 13 & 32.4 & \\
\hline & $\mathrm{SD}$ & 1.52 & 2.44 & & 2.42 & 7.23 & \\
\hline \multirow{4}{*}{$\begin{array}{l}\text { Insufficiency } \\
25(\mathrm{OH}) \text {-vitamin-D: } 20-29 \mathrm{ng} / \mathrm{ml}\end{array}$} & Min & - & - & \multirow{4}{*}{0} & 26.5 & 25 & \multirow{4}{*}{2} \\
\hline & Max & - & - & & 28.6 & 34 & \\
\hline & Mean & - & - & & 27.5 & 29.5 & \\
\hline & SD & - & - & & 1.48 & 6.36 & \\
\hline \multirow{4}{*}{$\begin{array}{l}\text { Average } \\
25(\mathrm{OH}) \text {-vitamin-D } \geq 30 \mathrm{ng} / \mathrm{ml}\end{array}$} & Min & - & - & \multirow{4}{*}{0} & 31.1 & 24 & \multirow{4}{*}{3} \\
\hline & Max & - & - & & 34.7 & 38.5 & \\
\hline & Mean & - & - & & 33.25 & 31.8 & \\
\hline & SD & - & - & & 2.05 & 7.32 & \\
\hline
\end{tabular}

Comparison of 25(OH)-D status between ASD and control children

The mean level of 25(OH)-D in ASD group was 16.3 $\mathrm{ng} / \mathrm{ml} \pm 12.3$ (ranged from 4.67 to $63.5 \mathrm{ng} / \mathrm{ml}$ ), while in the control group $40 \mathrm{ng} / \mathrm{ml} \pm 14$ (ranged from 14 to $70 \mathrm{ng} / \mathrm{ml}$ ). Our results revealed that ASD group have lower 25(OH)-D than control group with significant difference $(P<0.001$, $\mathrm{t}=7, \mathrm{df}=70$ with $95 \%$ confidence interval -29.9 to -17.5 ) as shown in (Figure 1). The ASD group showed severe deficiency of 25(OH)-D in 10 children, deficiency in 17 children, and insufficiency in 6 children. The 25(OH)-D level was average only in 3 ASD children. In contrast, none of the control group showed severe deficiency, only 4 children showed deficiency, 6 children showed insufficiency and 26 children had average 25(OH)-D. Other descriptive statistics for the $25(\mathrm{OH})$-D statuses in both groups were shown in Table (3).

Figure (1) showed results of the unpaired t-test comparison between autistic and control children $(n=36$ each). Note that autistics have significantly lowered $25(\mathrm{OH})$ vitamin D status compared to the controls. ASD: autism spectrum disorder.

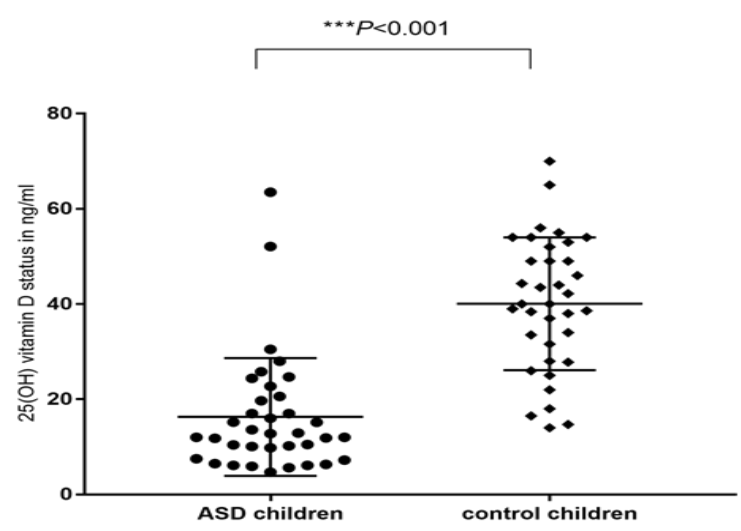

Fig. 1: comparison of 25(OH)-D between autistic and control children.

\section{Comparison of 25(OH)-D statuses between control and $A S D^{\prime}$ mothers}

The mean serum 25(OH)-D in ASD' mothers was 8.6 with SD $3.38(8.6 \pm 3.38)$, in contrast, that of the control mothers was (13.46 \pm 9.47 ) as shown in (Figure 2). The mean serum 25(OH)-D in ASD' mothers was lower than that of the control mothers with significant difference $(P=0.025)$. However, $79.16 \%$ of the control mothers (19/24) still have vitamin D deficiency $(<20 \mathrm{ng} / \mathrm{ml})$ (Figure 2).

Figure (2) showed results of the unpaired t-test comparison between mothers of autistic children and control mothers ( $n=24$ each). Note that ASD' mothers have significantly lower $25(\mathrm{OH})$ vitamin D status compared to the controls. ASD: autism spectrum disorder.

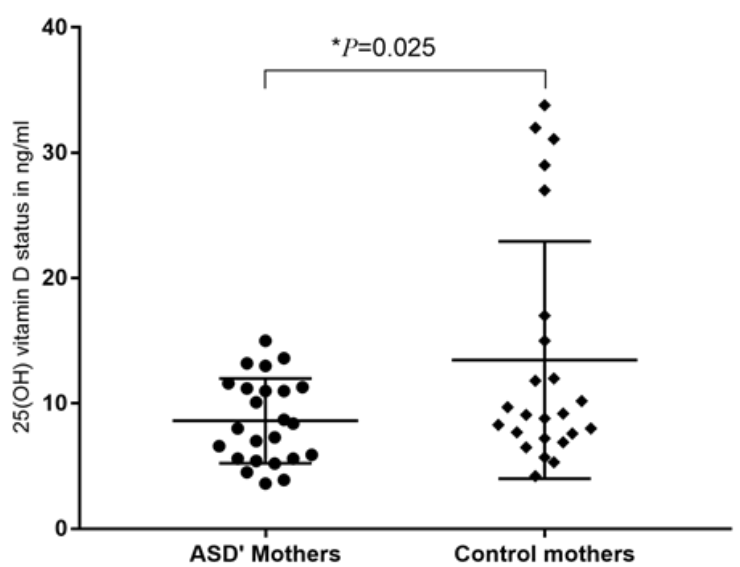

Fig. 2: comparison between ASD' mothers and control mothers.

\section{Correlation between 25(OH)-D status and severity of $A S D$}

Assessment of ASD severity by DSM-V and GARS showed that 17 subjects $(47.2 \%)$ have severe ASD. These were scored 6 in the severity rating scale. The remaining 
subjects $19(52.7 \%)$ ranged from score 1 to 5 as shown in (Figure 3). Multidisciplinary clinical evaluation of the autistic children confirmed the diagnosis and the severity rating. Correlation of the $25(\mathrm{OH})-\mathrm{D}$ status in autistics to the ASD severity showed moderate negative correlation $(P=0.001$, Spearman $\mathrm{r}=-0.525)$. The two-tailed option was used in the test with $95 \%$ confidence interval $(-0.732$ to -0.228 ) (Figure 3).

Figure (3) showed correlation between 25(OH)vitamin-D statuses in autistic children and severity of ASD. The results revealed moderate negative correlation $(\mathrm{P}=0.001$ and Spearman $\mathrm{r}=-0.525)$. Note most of children with severe ASD have deficiency of $25(\mathrm{OH})$-vitamin-D (less than $20 \mathrm{ng} / \mathrm{ml}$ ).

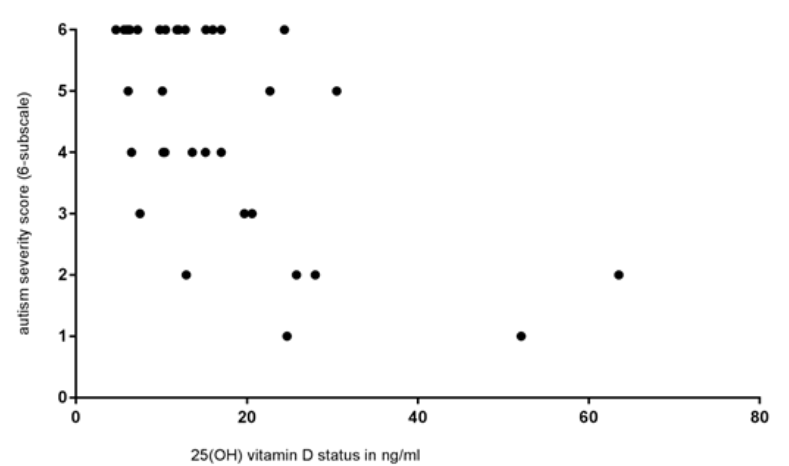

Fig. 3: correlation between $25(\mathrm{OH})$-vitamin-D status and severity of ASD.

\section{Correlation of 25(OH)-D statuses in autistic children and their mothers}

The mothers investigated showed an average level of $25(\mathrm{OH})-\mathrm{D}$ equal $14.4 \mathrm{ng} / \mathrm{ml}$ with $\mathrm{SD}=5.8(\mathrm{n}=24)$. The average 25(OH)-D level in the ASD group was $16.3 \mathrm{ng} /$ $\mathrm{ml}$ and SD 12.4. Correlation of the mothers' and their children's vitamin statuses revealed moderate-to-strong positive correlation $(P<0.001$, Pearson $r=+0.795)$. The two-tailed option of $P$ value was used with $95 \%$ confidence interval $(0.578$ to 0.907$)$. It was noticed that every mother had lower 25(OH)-D level than her ASD child (Figure 4).

Figure (4) showed correlation between the $25(\mathrm{OH})$ vitamin D statuses in autistic children and their mothers. The results revealed nearly strong positive correlation $(P<0.001$ and Pearson $\mathrm{r}=+0.795)$. Note the linear correlation fashion between the two statuses. ASD is stand for autism spectrum disorder.

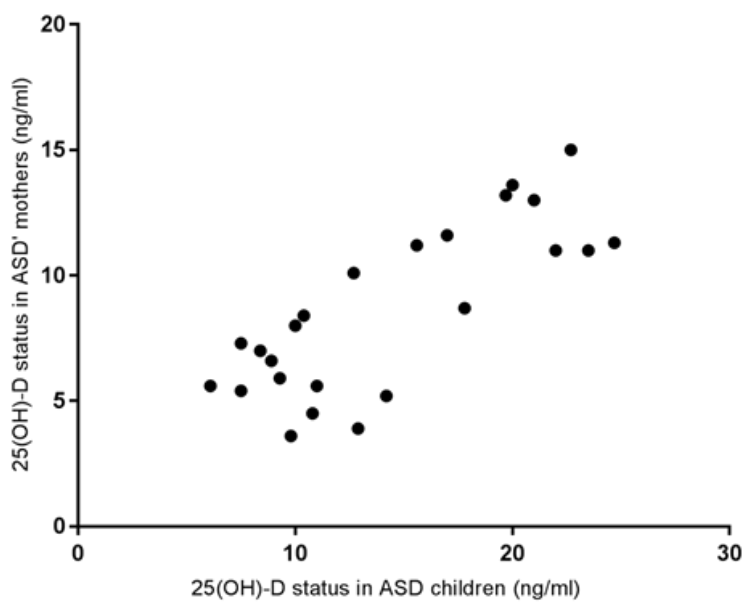

Fig. 4: correlation between $25(\mathrm{OH})-\mathrm{D}$ in autistic children and their mothers.

Comparison of the control children and control mother was illustrated in (Figure 5).

Figure (5) showed correlation between the $25(\mathrm{OH})$ vitamin $\mathrm{D}$ statuses in control children and control mothers. The results revealed no correlation $(P=0.504$ and Pearson $\mathrm{r}=+0.143$ ).

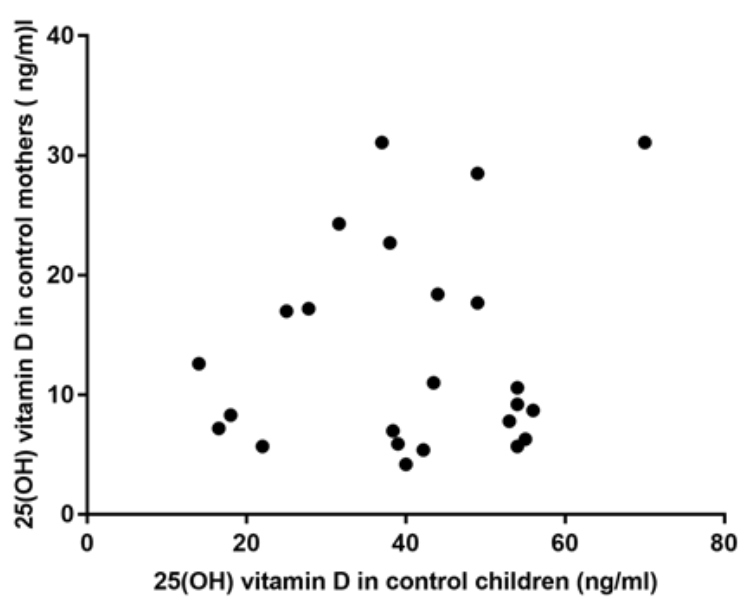

Fig. 5: correlation between $25(\mathrm{OH})-\mathrm{D}$ in control children and their mothers.

\section{DISCUSSION}

The exact etiology of ASD still not fully understood so far. Vitamin D plays vital roles in the brain development and function ${ }^{[12]}$. Researches in the last 15 years have 
yielded a large amount of knowledge about vitamin-D and its role in the brain development and function. For example, the distribution of the vitamin-D receptors (VDR) and the enzyme associated with the synthesis of the active form of the hormone [1- $\alpha$-hydroxylase (CYP27B1)] has been mapped in human brain with strong expression in cerebellum and in areas involved in cognitive function and social behavior (hippocampi, cingulated gyrus, prefrontal cortex, and temporal lobe, substantia nigra and supraoptic and paraventricular nuclei of the hypothalamus). This indicates that the brain has the potential to synthesize the active metabolite $1,25(\mathrm{OH}) 2-\mathrm{D} 3^{[18]}$.

Vitamin D can be considered as one of the neurosteroid which is very important in the development of the brain and maintaining its function ${ }^{[19,20]}$. Autism spectrum disorder is a neurodevelopmental disorder usually developed in late infancy and early childhood periods. Longstanding vitamin-D deficiency before this critical period of development could be possible cause for defective brain maturation and function, and consequently, the neurodevelopmental disorders like ASD. A previous study suggested that supplementing infants with Vitamin D3 might prove to be a safe and effective strategy for reducing the risk of $\mathrm{ASD}^{[21]}$. Similar study showed that $80.72 \%$ $(67 / 83)$ of the autistic children who received vitamin D3 treatment (5000 IU/day) showed significant improvement when serum 25(OH)-D level reach $40 \mathrm{ng} / \mathrm{ml}^{[22]}$. Relation of ASD to the vitamin D status in both mothers and children is lacking.

In the current research, we filled the gap by measuring vitamin $\mathrm{D}$ statuses in both mothers and children, also correlating between vitamin D status and severity of ASD. Our results revealed that ASD group have much lower 25(OH)-D level than the control group with significant difference. This result was consistent with previous researches ${ }^{[21,22,23]}$ that found ASD children have vitamin D deficiency and recommended vitamin D supplement. In addition, our results showed significant negative correlation between $25(\mathrm{OH})$-D level and severity of ASD. This means that the lower the vitamin-D level is the more severe autistic features will be. Again, this was in agreement with other previous researches ${ }^{[22,23]}$. In the current research, the mothers of autistic children showed deficiency of 25( $(\mathrm{OH})-\mathrm{D}$ as well. Surprisingly, every mother had her vitamin-D status even lower than that of her child. Both mothers and their autistic children have low 25(OH)-D statuses which were correlated to each other in a linear fashion showing moderate to strong positive correlation. This positive correlation may indicate that $25(\mathrm{OH})-\mathrm{D}$ statuses in autistic children were maternal-dependent. So, the deficiency of $25(\mathrm{OH})-\mathrm{D}$ in autistic children may be exist since birth as a continuum of intrauterine vitamin status for the fetus. Pet and Brouwer-Brolsma ${ }^{[24]}$ found that vitamin $\mathrm{D}$ diffuses through the placenta from mother to fetus, so, mothers was considered the only source of vitamin D substrate for the developing infant. Also, they found that maternal deficiency of vitamin D is associated with fetal vitamin deficiency as well.
Unlike the ASD children and their mothers, the statuses of 25(OH)-D in control children and their mothers were not correlated. This can be explained by the fact that positive correlation of 25(OH)-D in ASD and their mothers may not only be due to simple placental transfer but also may related to an underlying genetic defect common in mothers and ASD children. The possible gene defect might be related to synthesis of inactive vitamin D and the ASD itself. This may explain the correlated 25(OH)-D in ASD children and ASD' mothers but not in typically developed children and their mothers. A recent study investigated genetic control of gestational and neonatal 25-hydroxyvitamin $\mathrm{D}$ levels in mother-neonate pairs and found evidence for a genome-wide significant mutation located in the GC gene, which is fundamental for the vitamin D pathway, influencing neonatal vitamin D levels. Also, observation of an association between decreased neonatal vitamin D levels in children with intellectual disability from mothers with a specific genotype suggests that cross-genetic contribution in pregnancy might have a role in early risk for neurodevelopmental disorders ${ }^{[25]}$.

Lower serum maternal concentrations of $25(\mathrm{OH})-\mathrm{D}$ in the first trimester were associated with increased risk of developing ASD in offspring ${ }^{[26]}$. Also, strong association was found between maternal hypovitaminosis $\mathrm{D}$ and ASD with intellectual disability ${ }^{[15]}$. These previous results indicated the importance of the vitamin $\mathrm{D}$ for embryogenesis of the fetal brain. In the current research, the 25(OH)-D statuses showed deficiency in both autistic children and their mothers. Although their plasma levels of vitamin D were low, they showed significant moderate to strong positive correlation.

1a,25(OH)2D3 initiates biological responses via binding to the vitamin-D receptor (VDR). The VDR contains two overlapping ligand binding sites, a genomic pocket (VDR-GP) and an alternative pocket (VDR-AP). The VDR-GP interacts with the retinoid $\mathrm{X}$ receptor to form a heterodimer that binds to vitamin $\mathrm{D}$ responsive elements (VDRE) in the region of genes directly controlled by $1 \mathrm{a}, 25(\mathrm{OH}) 2 \mathrm{D} 3^{[27]}$. The VDRE can activate or repress many transcription factors which regulate neurotransmitter expression, neurotropic and growth factor synthesis. Vitamin D hormone appears to regulate the expression of 900 genes which are important for brain development ${ }^{[28]}$. Also, vitamin D has immunmodulatory function through modulation of the T-cell function ${ }^{[20]}$.

Hashimoto et al. ${ }^{[29]}$ reported that lesions in the amygdalohippocampal region in infants lead to manifestation of many autistic-like features. Also, amygdala lesions in humans are associated with difficulties in recognizing faces and exhibiting inappropriate social behaviors. Another histoanatomic study in autistic patients have revealed fewer than average purkinje cells in the cerebellum and anatomical abnormalities in the hippocampus, amygdala, entorhinal cortex, cingulate cortex, septal nuclei, and mamillary body ${ }^{[30]}$. Also, it has been reported that some autistic persons have mesolimbic, hippocampal, or cerebellar 
pathology which has been hypothesized to originate from dysregulation occurring during ontogenesis of the brain $^{[31]}$.

These anatomical abnormalities beside the high distribution of the vitamin-D receptors (VDR) and the enzyme associated with the synthesis of the active form of the hormone [1- $\alpha$-hydroxylase (CYP27B1)] in these areas (cerebellum, hippocampi, cingulated gyrus, prefrontal cortex, and temporal lobe and other parts of the limbic system) may put puzzles together. Vitamin D3 promotes typical development of the brain through regulation the synthesis of specific neurotrophins like nerve growth factor, neurotrophin 3 and glial cell-line derived neurotrophic factor $^{[24]}$. Generally speaking, the under-differentiation and anatomical abnormalities of these brain areas in autistic children could be secondary to vitamin D3 deficiency inutero and consequently in the postnatal period of brain development (infancy and early childhood periods).

Serotonin plays a major role in ASD [28]. Serotonin is synthesized from tryptophan by tryptophan hydroxylase enzyme (TPH $)^{[32,33]}$. There are two separate enzymes; TPH1 and TPH2, which are localized in different tissues and produced by different genes. TPH1 is found in nonbrain tissues, including the gut enterochromaffin cells and $\mathrm{T}$ cells. It is responsible for producing most of the serotonin found in the body, including the blood ${ }^{[34]}$.

TPH2 is entirely restricted to neurons ${ }^{[35]}$. Serotonin in the brain promotes prosocial behavior and corrects assessment of emotional social cues ${ }^{[36]}$. Brains of individuals with ASD display significantly lower concentrations of serotonin compared with the brains of non-autistic individuals ${ }^{[37]}$. Vitamin-D hormone is a key regulator of brain serotonin synthesis through TPH2, which contains a VDRE consistent with activation. This mechanism explains how low vitamin D hormone levels result in aberrant serotonin synthesis, subsequently leading to abnormal brain development ${ }^{[38]}$. Low vitamin D hormone levels during fetal and neonatal development could result in poor TPH2 expression and subsequently reduced serotonin concentrations in the developing brain which cause poor social interaction in $\mathrm{ASD}^{[28]}$. On the other hand, vitamin D represses the transcription of TPH1 which is located peripherally in the platelets, $\mathrm{T}$ cells, and enterochromaphin cells in the gut. Hence, large numbers of autistic children have hyperserotonemia in the blood and anomalies in gasterointestinal tract secondary to abnormal activation of the T cells ${ }^{[39]}$.

Although, both genetic and environmental factors were reported as possible causes of ASD, there were mounting evidences that environmental factors were more relevant than genetic factors for the development of $\mathrm{ASD}^{[40]}$. In the current research, the deficiency of $25(\mathrm{OH})-\mathrm{D}$ in both children and their mothers was found to be associated with high risk for ASD. The deficiency of vitamin-D3 hormone in early life adversely affects the expression of neurotransmitters and many genes that responsible for intact brain development, maturation and function ${ }^{[27,28]}$.
Generally speaking, the etiology of ASD may run in the environmental-genetic axis. There were evidences for some improvement of autistic children after vitamin D3 supplementation ${ }^{[18,19]}$.

In summary, autistic children and their mothers have significant $25(\mathrm{OH})-\mathrm{D}$ deficiency compared to typically developed children and their mothers. The status of 25(OH)-D in autistic children are inversely correlated to the severity of ASD. Also, vitamin statuses in ASD children have direct correlation with their mothers' statuses. This correlation was not found in the control groups. So, vitamin deficiency in ASD children could be genetically based from their mothers. The deficiency of 25(OH)-D in autistic children may be the primary predisposing factor for ASD. Also, it may be responsible for the common anatomical, biochemical, immunological, gastrointestinal and genetic factors reported in ASD and accounting for their corresponding clinical presentations. For example, vitamin $\mathrm{D}$ deficiency may relate to underdevelopment of VDR-rich areas like hypothalamus and limbic system with the consequent sensory and emotional abnormalities in ASD. Also, vitamin D deficiency may be responsible for reduced brain serotonin synthesis; hence, the poor face recognition and social cues in ASD. The hyperserotinemia and constipation reported in autistic children might be related to vitamin $\mathrm{D}$ deficiency which results in reduced repression of TPH1. Also, 25(OH)-D have immunomdulatory function; hence, its deficiency may be responsible for low immunity and repeated infection in autistics. Moreover, deficiency of 25(OH)-D may explain the genetic theory because vitamin $\mathrm{D}$ plays a vital role in regulation of many genes which responsible for brain development. Therefore, vitamin D deficiency may alter these genes which adversely affect brain development. Generally speaking, vitamin D deficiency may be considered the primary predisposing factor for ASD. Small sample size is a limitation of our study. Further researches are required to evaluate the relation of $25(\mathrm{OH})$-D status to the underlying abnormalities in ASD. Also, genetic study may be needed to evaluate an underlying genetic cause for vitamin D deficiency in autistic children and their mothers.

\section{CONCLUSION}

In conclusion, autistic children and their mothers have low 25(OH)-D than the control groups. The vitamin D deficiency in autistic children could be maternal-dependent as a continuum of the fetal vitamin status. Vitamin D deficiency in-utero and in early life adversely affects the brain development and function. Low vitamin D statuses in both mothers and their children were associated with ASD. This deficiency of vitamin D in autistic children and their mothers may be the primary predisposing factors for ASD. Early vitamin D3 supplementation is highly recommended for vitamin D-deficient pregnant mothers and autistic infants. Further longitudinal study is recommended to evaluate the clinical outcomes of ASD children following early vitamin D3 supplementation. 


\section{DATA AVAILABILITY}

The subject data used to support the findings of this study are restricted by the Ethical Committee Board of the Faculty of Medicine, Sohag University in order to protect patient privacy. Data are available from [Megahed Hassan, email: megahed_hassan@med.sohag.edu.eg] for researchers who meet the criteria for access to confidential data.

\section{CONFLICT OF INTERESTS}

There are no conflicts of interest.

\section{ACKNOWLEDGMENT}

The authors here acknowledge the psychologists by names (Walaa Eldesouky, Rasha Mohamed and Hoda Hassan) and appreciate their efforts in this research.

\section{REFERENCES}

1. American Psychiatric Association (APA). Diagnostic and statistical manual of mental disorders: DSM-IV-TR. Washington, DC: American Psychiatric Association; 2000.

2. Banerjee A, Engineer C T, Sauls B L, Morales A A, Kilgard M P, Ploski J E. Abnormal emotional learning in a rat model of autism exposed to valproic acid in utero, Behavioral Neuroscience, 2014; 8 (387): 1 - 14.

3. Shao Y., Wolpert C.M., Raiford K.L., Menold M.M., Donnelly S.L., Ravan S.A., et al. Genomic screen and follow-up analysis for autistic disorder. Am J of Med Genet, 2002; 114(1): 99 - 105.

4. Szatmari, P. The causes of autism spectrum disorder, British medical journal, 2003; 326(7382): 173 - 174.

5. Lichtenstein P., Carlstrom E. Rastam M., Gillberg C., Anckarsater H. The genetics of autism spectrum disorders and related neuropsychiatric disorders in childhood. Am J Psychiatry, 2010; 167(11):1357 - 1363.

6. Croen L.A., Yoshida C. K., Odouli R., Newman T. B. Neonatal hyperbilirubinemia and risk of autism spectrum disorders. Pediatrics, 2005; 115(2): $135-138$.

7. Larsson M., Weiss B., Janson S., Sundell J. and Bornehag $\mathrm{C}$ G. Association between indoor environmental factors and parental-reported autistic spectrum disorders in children 6-8 years of age. Neurotoxicology, 2009; 30(5): $822-831$.

8. Bromley R., Mawer G., Clayton-Smith J., Baker G. et al., (2008): Autism spectrum disorders following in utero exposure to antiepileptic drugs. Neurology, 2008;71(23): 1923 - 1924

9. Newschaffer C. J., Croen L. A., Daniels J., Giarelli E., Grether J. K., Levy S. E. et al. The epidemiology of autism spectrum disorders. Annu Rev Public Health, 2007; 28: $235-258$.
10. Shah P., Dalton R. and Boris N. Pervasive developmental disorders and childhood psychosis. In: Kliegman RM, Behrman RE, Jenson HB, Stanton BF, (Eds). Nelson Textbook of Pediatrics. 18th edition. Philadelphia, Pa: Saunders Elsevier, 2007; chapter 29: $1243-1252$.

11. Blann A. Vitamin D deficiency in women. British J Family Medicine, 2015.

12. Eyles D. W., Burne T. H., McGrath J. J. Vitamin D, effects on brain development, adult brain function and the links between low levels of vitamin D and neuropsychiatric disease. Front Neuroendocrinol 2013; 34(1): $47-64$.

13. Eyles D.W, Feron F, Cui X, Kesby J. P., Harms L. H., Ko P., et al. Developmental vitamin D deficiency causes abnormal brain development. Psychoneuroendocrinology, 2009; 34(1): S247 - 257.

14. Magnusson C, Lundberg M, Lee B. K, Rai D, Karlsson H, Gardner R, et al. Maternal vitamin D deficiency and the risk of autism spectrum disorders: population-based study. BJPsych Open, doi:10.1192/ bjpo.bp.116.002675, 2016; 2(2): 170 - 172.

15. American Psychiatric Association (APA). Diagnostic and statistical manual of mental disorders: DSM-V. Washington, DC: American Psychiatric Association, 2013.

16. Gilliam J. GARS-2: Gilliam Autism Rating Scale-Second Edition. Austin, TX: PRO-ED. 2006.

17. Holick M F. Vitamin D deficiency. N Engl J Med, 2007; 357(3): $266-281$.

18. Eyles D. W, Smith S, Kinobe R., Hewison M., McGrath J. J. Distribution of the vitamin D receptor and $1 \alpha$-hydroxylase in human brain. Journal of Chemical Neuroanatomy, 2005; 29: 21 - 30.

19. McCann J. C., Ames, B. N. Is there convincing biological or behavioral evidence linking vitamin D deficiency to brain dysfunction? FASEB J, 2008; 22(4): 982 - 1001.

20. Holick M. F., Chen, T. C. Vitamin D deficiency: a worldwide problem with health consequences. Am. J. Clin.Nutr, 2008; 87(4): 1080S - 1086S

21. Bener A, Khattab A O, Al-Dabbagh M M. Is high prevalence of Vitamin D deficiency evidence for autism disorder?: In a highly endogamous population. J Pediatric Neurosciences, 2014; 9(3): 227 - 233.

22. Saad K, Abdel-rahman A A, Elserogy Y M, Al-Atram AA, Cannell J J, Bjorklund G, et al. Vitamin D status in autism spectrum disorders and the efficacy of vitamin D supplementation in autistic children. Nutritional Neuroscience, 2016; 19(8): 346 - 351. 
23. Mostafa G A, Al-Ayadhi L Y. Reduced serum concentrations of 25-hydroxy vitamin $\mathrm{D}$ in children with autism: relation to autoimmunity. J Neuroinflammation, 2012; 9: 201.

24. Pet MA and Brouwer-Brolsma EM (2016) The Impact of Maternal Vitamin D Status on Offspring Brain Development and Function: a Systematic Review. Advances in nutrition 7(4): 665-78.

25. Traglia M, Windham GC, Pearl M, Poon V, Eyles D, Jones KL, et al. Genetic Contributions to Maternal and Neonatal Vitamin D Levels. Genetics J, 2020; 214(4): 1091 - 1102.

26. Chen J, Xin K, Wei J, Zhang K, Xiao H. Lower maternal serum $25(\mathrm{OH}) \mathrm{D}$ in first trimester associated with higher autism risk in Chinese offspring. J of Psychosomatic Research, 2016; 89: 98 - 101.

27. Haussler M R, Jurutka P W, Mizwicki M, Norman A W. Vitamin D receptor (VDR)-mediated actions of $1 \alpha, 25(\mathrm{OH}) 2$ vitamin D3: Genomic and non-genomic mechanisms. Best Practice \& Research Clinical Endocrinology \& Metabolism, 2011; 25(4): 543 - 559.

28. Patrick, R. P, Ames, B. N. Vitamin D hormone regulates serotonin synthesis, Part 1: relevance for autism, The FASEB Journal Review, 2014; 28(6): 2398 - 2413. doi: 10.1096/fj.13-246546.

29. Hashimoto T., Tayama M., Murakawa K., Yoshimoto T., Miyazaki M., Harada M. Development of the brainstem and cerebellum in autistic patients. J Autism DevDisord 1995; 25(1):1-18.

30. Bauman M and Kemper TL (1985) Histoanatomic observations of the brain in early infantile autism. Neurology 35(6): 866-874.

31. RiikonenR., and Vanhala R. Levels of cerebrospinal fluid nerve-growth factor differ in infantile autism and Rett syndrome. Developmental Medicine and Child Neurology 1999; 41: 148-152.
32. Schaaf, C. P., and Zoghbi, H. Y. Solving the autism puzzle a few pieces at a time. Neuron, 2011; 70(5): 806 - 808. doi: 10.1016/j.neuron.2011.05.025.

33. Hallmayer J., Cleveland S., Torres A., Phillips J., Cohen B., Torigoe T. et al. Genetic heritability and shared environmental factors among twin pairs with autism. Arch. Gen. Psychiatry, 2011; 68(11): 1095 - 1110 .

34. Gutknecht L., Kriegebaum C., Waider J., Schmitt A., and Lesch K. P. Spatio-temporal expression of tryptophan hydroxylase isoforms in murine and human brain: convergent data from Tph2 knockout mice. Eur. Neuropsychopharmacology, 2009; 19(4): 266 - 282.

35. Crockett, M. J. The neurochemistry of fairness: clarifying the link between serotonin and prosocial behavior. Ann. N.Y. Acad. Sci, 2009; 1167: 76-86.

36. Chugani D. C., Muzik O., Behen M., Rothermel R., Janisse J. J., Lee J., Chugani, H. T. Developmental changes in brain serotonin synthesis capacity in autistic and nonautistic children. Ann. Neurol, 1999; 45(3): $287-295$.

37. Boylan C. B., Blue, M. E., Hohmann, C. F. Modeling early cortical serotonergic deficits in autism.Behav. Brain Res, 2007; 176(1): 94-108.

38. Walther, D. J., and Bader, M. (2003) A unique central tryptophan hydroxylase isoform. Biochem. Pharmacol, 2003; 66(9): 1673 - 1680.

39. Gershon M. D. Serotonin is a sword and a shield of the bowel: serotonin plays offense and defense. Trans. Am. Clin. Climatol. Assoc, 2012; 123(280): 268 - 280.

40. Robinson E. B., Samocha K. E., Kosmicki J. A., McGrath L., Neale B. M., Perlis R. H., et al. Autism spectrum disorder severity reflects the average contribution of de novo and familial influences. Proc. Natl. Acad. Sci. USA, 2014; 111(42): 15161 - 1565. 